Article

\title{
Coffee Consumption among Adults in the United States by Demographic Variables and Purchase Location: Analyses of NHANES 2011-2016 Data
}

\author{
Colin D. Rehm ${ }^{1}$, Joseph C. Ratliff ${ }^{2}$, Claudia S. Riedt ${ }^{2}$ and Adam Drewnowski ${ }^{3, *}$ \\ 1 Department of Epidemiology \& Population Health, Albert Einstein College of Medicine, \\ Montefiore Medical Center, Bronx, NY 10595, USA; colin.rehm@gmail.com \\ 2 Keurig Dr Pepper, 5301 Legacy Drive, Plano, TX 75024, USA; joseph.ratliff@kdrp.com (J.C.R.); \\ Claudia.Riedt@kdrp.com (C.S.R.) \\ 3 Center for Public Health Nutrition, University of Washington, Box 353410, Seattle, WA 98195, USA \\ * Correspondence: adamdrew@uw.edu
}

Received: 1 July 2020; Accepted: 13 August 2020; Published: 16 August 2020

\begin{abstract}
Coffee, obtained from various sources, is consumed by most United States adults. The present analyses of one and two 24 -h dietary recalls for 14,865 persons aged $\geq 20$ years in the 2011-2016 National Health and Nutrition Examination Survey (NHANES 2011-2016) aimed to identify socio-demographic predictors of coffee consumption and to examine whether coffee purchase locations differed by population sub-group. Given the emphasis on food and beverage consumption patterns, the relation between coffee consumption and compliance with the Dietary Guidelines of Americans was also examined. Coffee was consumed by $59 \%$ of the sample $(n=8551)$. Survey-adjusted mean intake among consumers was $544.7 \mathrm{~g} / \mathrm{day}$. Percent consumers and mean amounts consumed were highest among adults aged 51-70 years $(p<0.001)$, higher income groups $(p<0.001)$, and non-Hispanic Whites $(p<0.001)$. About $74 \%$ of coffee consumers obtained their coffee from stores, $9.8 \%$ from fast food restaurants, $4.3 \%$ from convenience stores, and $4.2 \%$ from someone else. Coffee source locations also varied by age, education, income, and race/ethnicity. Coffee consumers had significantly higher Healthy Eating Index (HEI-2015) and higher Nutrient-Rich Foods (NRF9.3) scores in energy-adjusted models and significantly higher HEI 2015 scores in multivariable models. In multivariable models, coffee consumers had diets with less added sugar $(p<0.001)$ but slightly more fat (of all types, including monounsaturated (MUFA), polyunsaturated (PUFA), saturated and solid fats), cholesterol, and alcohol. Their diets had more potassium and magnesium $(p<0.001)$ but less vitamin $C(p<0.001)$. Mean caffeine consumption was $233 \mathrm{mg} /$ day for consumers and $72.3 \mathrm{mg} / \mathrm{day}$ for non-consumers. Coffee consumption patterns in the US vary across socio-demographic groups.
\end{abstract}

Keywords: coffee; demographics; socioeconomic status; diet quality; caffeine; Nutrient-Rich Foods (NRF9.3); Healthy Eating Index 2015; purchase location

\section{Introduction}

Coffee and tea, along with plain drinking water, are among the most frequently consumed beverages in the world [1]. Analyses of the National Health and Nutrition Examination Survey (NHANES) data for years 2003-2012 showed that 75\% of US adults aged $\geq 20$ years consumed coffee [2]. By contrast, analyses of NHANES data for years 2011-2016 showed than only 20.8\% of adults aged $>20$ years drank tea [3]. Mean coffee consumption among coffee drinkers was estimated at $417 \mathrm{~mL} /$ day [2]; mean tea consumption among tea drinkers was estimated at 91.6 g/day [3,4]. Water consumption easily exceeded that of coffee and tea combined. In the NHANES 2015-2016 data, mean intake of plain drinking water, bottled and tap, among adults was estimated at $1271 \mathrm{~mL} / \mathrm{day}$ [3]. 
The consumption of plain water, coffee, and tea in the US varied with age, race/ethnicity, education, and incomes [2-4]. In the NHANES 2003-2012 data, coffee consumption was higher in older age groups and among non-Hispanic Whites [2]. No effects of education or income were observed [2]. In the NHANES 2011-2016 data, tea consumption was higher in older age groups and among non-Hispanic Whites and Asians than among non-Hispanic Blacks or other groups [4]. Both tea consumption and flavonoid intakes were linked to higher socio-economic status [4,5]. Interestingly, a socioeconomic gradient was also observed for the consumption of plain water from the tap [3]. In the NHANES 2011-2016 data, tap water intake was higher among non-Hispanic Whites and higher income groups [3].

The current socioeconomic characteristics of coffee consumption in the US have been difficult to pin down. Some studies of beverage consumption trends in the US have aggregated brewed tea and coffee into a single category [6]. Exposure was defined in terms of high coffee consumption versus low (or no) coffee consumption [7]. Elsewhere, coffee consumers in NHANES 2003-2012 data were identified using a combination of food frequency questionnaires and 24-h dietary recalls [2]. Socio-economic status was dichotomized into more than high school diploma or high school diploma or less [2]. Numerous other studies have focused on caffeine intakes as opposed to the consumption of coffee and coffee beverages [8-10]. Although coffee is the largest single source of caffeine by far, caffeine is also present in sweetened beverages and in energy drinks [11].

Consumption surveys conducted by the coffee industry suggest that $64 \%$ of Americans aged 18 years and older drink a cup of coffee every day, and $79 \%$ of them drink coffee at home [12]. Coffee consumption increased with age, with $72 \%$ of adults over $60 \mathrm{y}$ classed as coffee drinkers [12]. Workplace consumption has increased from 16\% in 2013 to $21 \%$ in 2015 according to the National Coffee Data Trends Report that is available for purchase [13]. Consumer panel data also suggest that the younger demographics consume more coffee away from home [12,13].

The present analyses examined whether similar trends would be found in multiple years of the NHANES data. As the premier US program for monitoring population diet [14], the NHANES serves as the evidence base for nation-wide dietary recommendations and guidelines [15]. This study used dietary data from NHANES 2011-2016 to explore coffee consumption patterns across different socio-demographic groups and by purchase or sourcing location [16-18].

Given that foods and beverages are consumed as part of dietary patterns, the Dietary Guidelines 2015-2020 [15] raised the issue of whether coffee consumption was associated with additional calories from milk, cream, added sugars, or other additions that would need to be accounted for within the eating pattern. Secondary analyses addressed coffee consumption patterns in relation to sugar and fat intakes, compliance with the Dietary Guidelines for Americans, and other diet quality measures [4-6].

\section{Materials and Methods}

\subsection{Dietary Intake Databases}

Consumption data for coffee and coffee beverages came from 3 cycles of the National Health and Nutrition Examination Survey (NHANES), for the years 2011-2012, 2013-2014, and 2015-2016 [14]. The three NHANES cycles provided a total sample of 29,902 persons. The present analyses were based on 14,865 persons who were aged $\geq 20$ years and had at least one valid $24 \mathrm{~h}$ dietary recall as defined by NHCS staff. Two-day means for all dietary variables were calculated for respondents with two $24 \mathrm{~h}$ dietary recalls, in line with previously published methods [19]. The present analyses were based on 8551 persons who were aged $\geq 20$ years and had consumed any amount of coffee on one or both of their recall days.

The $24 \mathrm{~h}$ recall in NHANES studies is administered by trained interviewers, using a computerized interface. Participants are asked to report the types and amounts of all food and beverages consumed in the preceding $24 \mathrm{~h}$, from midnight to midnight [20]. The multi-pass method had respondents first identify a quick list of foods and beverages consumed. The time and consumption occasion for each food item were also obtained. The following passes asked for amounts consumed, and a final probe 
asked for any forgotten foods. Day 1 interviews were conducted in a mobile examination setting. Day 2 interviews were done by telephone some days later [21]. The mean number of days between the two dietary recalls was 7.9 days (median 5 days).

\subsection{Participant Characteristics}

NHANES participants were stratified by age, gender, education, family income-to-poverty ratio (IPR) and race/ethnicity. The age group cut points were: $20-30,31-50,51-70$, and $>70$ years. Gender was defined as male/female. Education was defined as $<$ high school; high school; some college; and completed college. Family IPR is the ratio of family income to the federal poverty threshold. In 2016, federal poverty level was defined as annual income of USD 24,300 for a family of 4 . The cut points for IPR were $<1 ; 1-1.99 ; 2-3.49$; and $\geq 3.5$. Race/ethnicity was defined as non-Hispanic White; non-Hispanic Black, Mexican American, Other Hispanic, non-Hispanic Asian, and other/mixed race.

\subsection{Defining Coffee Consumers}

The NHANES 24-h recall data provide the amounts in grams of each food and beverage consumed [14]. Coffee consumption was defined based on the What We Eat in America (WWEIA) Food Categorization scheme, which breaks all foods consumed into 155 categories. A few non-coffee containing beverages included in the WWEIA coffee category were excluded (e.g., postum and chicory). Coffee consumers were identified as those NHANES participants who had consumed any amount of coffee on one or both of their recall days. Based on these criteria, the final sample of coffee consumers was 8551.

Given that the place where the coffee was prepared or purchased was of interest, we excluded the small number of ready-to-drink canned/bottled coffees ( $<0.5 \%$ of all consumed coffee).

\subsection{Defining Source Locations for Coffees}

For each food/beverage in the 24-h recall, NHANES respondents also reported the source location. Those were assigned in the database into 26 categories including store, fast food restaurant, full-service restaurant, convenience store, common coffee pot, from someone else/gift, and mail order, among others.

The present analyses were based on 8 distinct sources. Those were: stores (including mail order), fast-food restaurants, convenience stores, from someone else/gift, restaurant, common coffee pot, cafeteria, and an additional other category. Coffee from someone else normally referred to drinking coffee at somebody's house, away from home. In rare instances where the coffee and coffee additions came from difference sources, the source of the coffee was the default option. The place of consumption (home vs. away from home) was used as an additional variable. As individuals could obtain coffee from multiple sources, we estimated the mean grams of coffee (and additions) from each source and at the population-level estimated the population ratio of coffee consumption from that source.

\subsection{Diet Quality Indicators}

The energy and nutrient content of the diet were calculated using the USDA Food and Nutrient Database for Dietary Studies (FNDDS) [22]. Data from the Food Patterns Equivalents Database (FPED) from the United States Department of Agriculture (USDA) [23] were used to estimate intakes of food groups (e.g., vegetables or fruit) in order to calculate Healthy Eating Index HEI-2015 scores.

The HEI-2015 [24] is an energy-adjusted measure of diet quality that is based on the intake of 9 food groups/nutrients to encourage and 4 food groups/nutrients to limit. Total fruits, whole fruits, total vegetables, greens and beans, whole grains, dairy, total protein foods, seafood and plant protein, and fatty acids ratio are the 9 items to encourage. Refined grains, sodium, added sugars and saturated fat are the 3 items to limit. The HEI-2015 is an operationalized measure of compliance with the 2015-2020 Dietary Guidelines for Americans.

The second measure of diet quality was provided by the Nutrient-Rich Foods (NRF9.3) index [25]. The NRF9.3 score is based on two subscores: the positive nutrient rich (NR) subscore and the negative 
nutrients to limit (LIM) subscore. The NR subscore contains 9 nutrients to encourage whereas the LIM subscore contains 3 nutrients to limit. The US Food and Drug Administration (FDA) and other standards were used to establish daily values, expressed as percentages. The reference amounts were: protein $(50 \mathrm{~g})$, fiber $(28 \mathrm{~g})$, calcium $(1300 \mathrm{mg})$, iron $(18 \mathrm{mg})$, potassium $(4700 \mathrm{mg})$, magnesium $(420 \mathrm{mg})$, vitamin A (900 RAE), vitamin C (90 mg), and vitamin D (20 mcg). For the 3 nutrients to limit the maximum recommended values (MRVs) were: saturated fat $(20 \mathrm{~g})$, added sugar $(50 \mathrm{~g})$ and sodium (2300 mg). The NRF9.3 formula was calculated as:

$$
\text { NRF9.3 }=(\text { NR9 }- \text { LIM }) \times 100
$$

where

$$
\begin{gathered}
N R=\sum_{i=1}^{9} \frac{\frac{\text { Intake }_{i}}{\text { Energy }} \times 2000}{D V_{i}} \\
L I M=\sum_{i=1}^{3} \frac{\frac{\text { Intake }_{i}}{\text { Energy }} \times 2000}{M R V_{i}}-1
\end{gathered}
$$

where Intake $e_{i}$ is the daily intake of each nutrient $i$ and $D V_{i}$ is the reference daily value for that nutrient. In calculating the NR subscore, each daily nutrient intake $i$ was adjusted for $2000 \mathrm{kcal}$ and expressed in percentage of DV. Following past protocol, percent DVs for nutrients were truncated at 100 , so that an excessively high intake of one nutrient could not compensate for the dietary inadequacy of another. In calculating LIM, only the share in excess of the recommended amount was considered.

\subsection{Data Availability and Ethical Approval}

The National Center for Health Statistics (NCHS) and its Institutional Review Board (IRB) provided the needed approval for NHANES protocols [26]. Written informed consent was provided by adult participants. All NHANES data are publicly available and posed on the NCHS and USDA websites [27]. According to the University of Washington (UW) policies, analyses of public data do not involve "human subjects" and do not require IRB review or an exempt determination. Such data may be used and analyzed without any involvement of the Human Subjects Division or the UW Institutional Review Board.

\subsection{Statistical Analyses}

The survey-weighted mean intakes of coffee were evaluated overall and by gender, age group, race/ethnicity, family IPR and education. Energy and nutrient intakes of coffee consumers $(n=8551)$ were compared to those of non-consumers $(n=6314)$. Similar analyses were used to examine coffee consumption broken into survey-weighted tertiles with a fourth category for non-coffee consumers.

Differences between survey-weighted means and proportions were tested using Wald tests and multivariable adjusted analyses were conducted using survey-weighted linear regression models with adjusted means represented as the marginal mean holding all covariates fixed as the approximate population-level average. Levels of statistical significance are indicated in the tables. All analyses accounted for the complex survey design of NHANES and reflect dietary behaviors of the US adult population from 2011-2016. All analyses were conducted using Stata 16.0 (College Station, TX, USA).

\section{Results}

\subsection{Characteristics of Coffee Consumption among Adults Aged $>20$ years}

Coffee consumers were those NHANES 2011-2016 participants who drank coffee only on day one (6.1\% of those with two recalls), only on day two (6.6\% of sample with two recalls), or on both days 
( $48.3 \%$ of the sample with two recalls). The percent of coffee consumers aged $>20 \mathrm{y}$ in the total sample was $59.5 \%$ and the mean amount consumed was $324 \mathrm{~g} /$ day or 10.9 fluid oz.

Table 1 shows percent consumers and amounts consumed by socio-demographic characteristics of the NHANES sample. Age group and race/ethnicity had significant effects on percent consumers and amounts consumed. Among those $20-30$ years, 38.9\% drank coffee and the mean amount consumed was $164 \mathrm{~g} /$ day (5.5 fluid ounces). In the $\geq 71$ years age group, $74.3 \%$ drank coffee and the mean amount consumed was $361 \mathrm{~g} /$ day (12.2 fluid ounces). Among non-Hispanic Whites, 63.7\% drank coffee and the mean amount consumed was $386 \mathrm{~g} /$ day (13.0 fluid ounces). Among non-Hispanic Blacks, $37.7 \%$ drank coffee and the mean amount consumed was $140 \mathrm{~g} / \mathrm{d}$ (4.7 fluid ounces). Coffee consumption was higher at higher incomes. For lower income individuals below federal poverty threshold (IPR < 1.00), prevalence of consumption was 50.3\% and the mean amount was $252 \mathrm{~g} /$ day. (8.5 fluid ounces). For higher income individuals (IPR > 3.5), the prevalence of consumption was $64.4 \%$ and the mean amount consumed was $316 \mathrm{~g} /$ day. The prevalence of consumption was the same for women and men but men drank more coffee. No effect of education on the amount of coffee consumed was observed.

Table 1. Sample characteristics for all adults (age $\geq 20$ years) in NHANES, 2011-2016.

\begin{tabular}{|c|c|c|c|}
\hline & $\mathbf{n}$ & $\%$ Consumers & Mean g/day \\
\hline Total & 14,865 & 59.5 & 324 \\
\hline \multicolumn{4}{|l|}{ Age group } \\
\hline $20-30$ & 2850 & 38.9 & 164 \\
\hline $31-50$ & 5071 & 57.8 & 308 \\
\hline $51-70$ & 4873 & 69.2 & 430 \\
\hline$\geq 71$ & 2071 & 74.3 & 361 \\
\hline$p$-value & & $<0.001$ & $<0.001$ \\
\hline \multicolumn{4}{|l|}{ Gender } \\
\hline Male & 7223 & 58.7 & 357 \\
\hline Female & 7642 & 60.3 & 293 \\
\hline$p$-value & & 0.18 & $<0.001$ \\
\hline \multicolumn{4}{|l|}{ Race/ethnicity } \\
\hline Non-Hispanic white & 5786 & 63.7 & 386 \\
\hline Non-Hispanic black & 3343 & 37.7 & 140 \\
\hline Mexican-American & 2010 & 58.3 & 238 \\
\hline Other Hispanic & 1590 & 64.5 & 248 \\
\hline Non-Hispanic Asian & 1656 & 50.8 & 187 \\
\hline Other/mixed race & 480 & 59.9 & 325 \\
\hline$p$-value & & $<0.001$ & $<0.001$ \\
\hline \multicolumn{4}{|l|}{ Education $^{\mathrm{a}}$} \\
\hline$<$ High school & 3280 & 60.0 & 307 \\
\hline High school & 3257 & 57.7 & 319 \\
\hline Some college & 4533 & 56.8 & 323 \\
\hline$\geq$ College & 3787 & 63.4 & 338 \\
\hline$p$-value & & 0.002 & 0.39 \\
\hline \multicolumn{4}{|c|}{ Family income-to-poverty ${ }^{b}$} \\
\hline$<1.00$ & 3119 & 50.3 & 252 \\
\hline $1.00-1.99$ & 3601 & 56.0 & 287 \\
\hline $2.00-3.49$ & 2836 & 60.3 & 340 \\
\hline$\geq 3.5$ & 4101 & 64.4 & 364 \\
\hline Missing & 1208 & 59.7 & 316 \\
\hline$p$-value & & $<0.001$ & $<0.001$ \\
\hline
\end{tabular}

a There were eight individuals missing education data. ${ }^{\mathrm{b}}$ The IPR accounts for household size. Individuals with missing IPR data are excluded. 


\subsection{Coffee Consumers versus Non Consumers}

Among adults identified as coffee consumers $(n=8551)$, the average amount of coffee consumed was $544.7 \mathrm{~g} /$ day or $18.3 \mathrm{oz}$. Median consumption was $439 \mathrm{~g} /$ day (14.8 oz) and interquartile intervals were 265-690 g/day (8.9 oz to $23.2 \mathrm{oz}$ ). Amounts of coffee consumed varied across population subgroups. Men consumed more coffee on average than did women. The effect of age was significant $(p<0.001)$; coffee consumption peaked for the 51-70 y age group (620.4 g/day) and declined for the $\geq 71$ years age group (486 g/day). The amounts of coffee consumed also varied by race/ethnicity $(p<0.001)$. The non-Hispanic white population consumed most coffee (605.5 g/day or $20.3 \mathrm{oz})$. The least coffee was consumed by non-Hispanic Black (371.8 g/day) and non-Hispanic Asian groups (368.5 g/day or $12.4 \mathrm{oz})$.

Table 2 shows energy and nutrient intakes together with overall dietary quality scores for consumers and non-consumers of coffee. Nutrient values were adjusted for energy (Model 1) and multivariable analyses adjusted energy, age group, gender, race/ethnicity and family income to poverty ratio (Model 2). Energy and protein intakes of coffee consumers and non-consumers were not significantly different adjusting for covariates. Coffee consumers had diets with significantly less carbohydrate and less added sugar. However, their diets were higher in total fat $(p<0.01)$, PUFA $(p<0.05)$, MUFA $(p<0.01)$, saturated fat $(p<0.05)$, solid fat $(p<0.01)$ and cholesterol $(p<0.001)$. The observed differences in dietary fat content of the diet between coffee consumers and non-consumers, though statistically significant, were negligible (Total fat: $1.2 \mathrm{~g}$, PUFA: $0.3 \mathrm{~g}$, MUFA: $0.3 \mathrm{~g}$, SFA: 0.4 g).

Coffee consumers had diets with more potassium and magnesium $(p<0.001)$ but less vitamin $C(p<0.001)$. No differences for calcium and vitamin D were observed. Mean caffeine consumption was $233 \mathrm{mg} /$ day for consumers and $72.3 \mathrm{mg} /$ day for non-consumers $(p<0.001)$. Coffee consumers had higher Nutrient-Rich Foods (NRF9.3) scores than did non consumers: however, this difference was attenuated in adjusted models. Coffee consumers had higher Healthy Eating Index (HEI-2015) scores in the energy-adjusted analyses and the effect remained significant in the multivariable model $(p<0.01)$.

Table 3 shows energy, nutrient intakes, and diet quality scores by tertiles of coffee consumption with non-consumers as an additional category. Nutrient values were adjusted for energy, age, gender, race/ethnicity and family income to poverty ratio. Protein intakes were not significantly different by trend analyses. Total carbohydrates (trend $p<0.001$ ) and added sugars (trend $p<0.01$ ) declined significantly with increasing coffee consumption. Higher coffee consumption was associated with diets that were higher in total fat $(p<0.001)$, PUFA $(p<0.001)$, MUFA $(p<0.001)$, solid fat $(p<0.001)$ and cholesterol $(p<0.01)$. Higher coffee consumption was associated with diets that were higher in potassium and magnesium $(p<0.001)$ but lower in vitamin $C(p<0.001)$. No differences for calcium and vitamin D were observed. Mean caffeine consumption increased from 125 to $380 \mathrm{mg} / \mathrm{day}$ on going from the first to the third tertile of coffee consumption.

In contrast to the comparison of consumers and non-consumers, the amount of coffee consumed had little to no impact on Nutrient-Rich Foods (NRF9.3) or on Healthy Eating Index (HEI-2015) scores. 
Table 2. Energy and nutrient intakes and nutrient density/diet quality scores (NRF and HEI) for coffee consumers $(\mathrm{N}=8551)$ and non-consumers $(\mathrm{N}=6314)$, NHANES 2011-2016

\begin{tabular}{|c|c|c|c|c|}
\hline & \multicolumn{4}{|c|}{ Mean $(95 \% \mathrm{CI})$} \\
\hline & \multicolumn{2}{|c|}{ Model 1 Energy-Adjusted ${ }^{a}$} & \multicolumn{2}{|c|}{ Model 2 Multivariable-Adjusted ${ }^{b}$} \\
\hline & Coffee Consumer $(n=8551)$ & Non-Consumer $(n=6314)$ & Coffee Consumer $(\mathrm{n}=8551)$ & Non-Consumer $(n=6314)$ \\
\hline Calories, kcal/day & $2065(2039,2091)^{* * *}$ & $2118(2091,2145)$ & $2089(2068,2111)$ & $2082(2061,2105)$ \\
\hline \multicolumn{5}{|l|}{ Macronutrients } \\
\hline Protein, g/day & $81.2(80.2,82.2)$ & $79.9(78.9,81)$ & $81.1(80.2,82)$ & $80(78.9,81.1)$ \\
\hline Carbohydrate, g/day & $235.4(233.4,237.4) * * *$ & $244.4(242.3,246.6)$ & $235.7(234.1,237.3) * * *$ & $244.1(241.7,246.4)$ \\
\hline Added sugar, teaspoon/day & $14.6(14.2,15) * * *$ & $16.5(16,17)$ & $14.8(14.5,15.2)^{* * *}$ & $16.1(15.6,16.6)$ \\
\hline Total fat, g/day & $77.2(76.6,77.9)^{* * *}$ & $75.5(74.7,76.2)$ & $77(76.5,77.6)^{* *}$ & $75.8(75,76.6)$ \\
\hline PUFA, g/day & $24.9(24.7,25.2) * * *$ & $24.3(24,24.7)$ & $24.8(24.6,25) *$ & $24.5(24.2,24.8)$ \\
\hline MUFA, g/day & $27.2(27,27.5) * * *$ & $26.4(26.1,26.7)$ & $27.2(26.9,27.4) * *$ & $26.5(26.2,26.9)$ \\
\hline SFA, g/day & $18.2(18,18.4)^{* * *}$ & $17.7(17.5,18)$ & $18.2(18,18.3) *$ & $17.8(17.6,18.1)$ \\
\hline Solid fat, g/day & $32.8(32.3,33.3) * * *$ & $31.7(31.1,32.2)$ & $32.7(32.3,33.2) * *$ & $31.8(31.3,32.3)$ \\
\hline \multicolumn{5}{|l|}{ Other dietary constituents } \\
\hline Caffeine, mg/day & $238.8(230.6,247.0) * * *$ & $63.9(57.9,69.8)^{* * *}$ & $233.0(226.5,239.6)^{* * *}$ & $72.3(66.4,78.2)$ \\
\hline Calcium, mg/day & $948.3(935.4,961.2)$ & $941.8(920,963.6)$ & $940.5(928.1,953)$ & $953.2(933.1,973.2)$ \\
\hline Potassium, mg/day & $2787.6(2753.4,2821.7)^{* * *}$ & $2466.6(2429.1,2504.1)$ & $2742.2(2713.9,2770.5)^{* * *}$ & $2533.2(2497.4,2569.1)$ \\
\hline Magnesium, mg/day & $313.2(308.3,318.1)^{* * *}$ & $285.7(281.2,290.3)$ & $309.4(305,313.8)^{* * *}$ & $291.3(286.5,296)$ \\
\hline Vitamin $C, \mathrm{mg} /$ day & $81.3(78.5,84.1)^{* *}$ & $86.4(82.4,90.5)$ & $80(77.5,82.4)^{* * *}$ & $88.4(84.3,92.6)$ \\
\hline Vitamin D, mcg/day & $4.8(4.6,4.9)$ & $4.6(4.4,4.8)$ & $4.7(4.5,4.8)$ & $4.7(4.5,4.9)$ \\
\hline Sodium, mg/day & $3397.3(3365.5,3429)$ & $3436.6(3397.5,3475.7)$ & $3400.7(3372.1,3429.3)$ & $3431.6(3393.4,3469.7)$ \\
\hline Cholesterol, mcg/day & $290.8(284.5,297)^{* * *}$ & $273.9(268.8,279.1)$ & $291.1(285.1,297)^{* * *}$ & $273.5(267.9,279.1)$ \\
\hline Alcohol, g/day & $9.5(8.7,10.3)^{* * *}$ & $7.1(6.4,7.8)$ & $9.6(8.9,10.2)^{* * *}$ & $7(6.2,7.8)$ \\
\hline \multicolumn{5}{|l|}{ Nutrient density/diet quality } \\
\hline NRF9.3 & $436.2(430.2,442.1)^{* * *}$ & $414.3(407.8,420.7)$ & $430(424.7,435.2)$ & $423.4(416.9,429.9)$ \\
\hline HEI-2015 & $52.9(52.3,53.5)^{* * *}$ & $50.4(49.8,50.9)$ & $52.3(51.9,52.8) * *$ & $51.2(50.6,51.8)$ \\
\hline
\end{tabular}

Abbreviations: MUFA monounsaturated fatty acids; PUFA polyunsaturated fatty acids; SFA saturated fatty acids; NRF Nutrient Rich Food Index; HEI-2015 Healthy Eating Index. a Adjusted for energy. Analyses of energy are not energy-adjusted. ${ }^{b}$ Adjusted for energy, age, gender, race/ethnicity and family income to poverty ratio. Asterisks indicate $p$-value comparing coffee consumers to non-consumers; ${ }^{* *} p<0.001$; ${ }^{* *} 0.001<p<0.01 ; * 0.01<p<0.05$. 
Table 3. Association between amount of coffee consumed (survey-weighted tertiles) and diet composition and diet quality measures.

\begin{tabular}{|c|c|c|c|c|c|}
\hline & \multicolumn{4}{|c|}{ Mean $(95 \% \mathrm{CI})^{\mathrm{a}}$} & \multirow{2}{*}{$p$-Trend } \\
\hline & $\begin{array}{l}\text { Non-Consumers } \\
\quad(n=6314)\end{array}$ & $\begin{array}{c}\text { T1 [1.3-319.2 g/day }] \\
(\mathrm{n}=3532)\end{array}$ & $\begin{array}{c}\text { T2 }[319.3-585 \mathrm{~g} / \text { day }] \\
(\mathrm{n}=2834)\end{array}$ & $\begin{array}{c}\text { T3 }[\geq 585.2 \mathrm{~g} / \text { day }] \\
(\mathrm{n}=2185)\end{array}$ & \\
\hline Calories, kcal/day & $2080(2057,2103)$ & $1997.6(1967,2029)$ & $2103.9(2063,2145)$ & $2172.7(2134,2211)$ & $<0.001$ \\
\hline \multicolumn{6}{|l|}{ Macronutrients } \\
\hline Protein, g/day & $80.1(79,81.2)$ & $81.6(80.2,83)$ & $81.2(79.8,82.6)$ & $80.5(79.3,81.6)$ & 0.484 \\
\hline Carbohydrate, g/day & $244.2(241.8,246.5)$ & $238.7(236.4,241.1)$ & $235.6(232.5,238.7)$ & $232.5(229.9,235)$ & $<0.001$ \\
\hline Added sugar, teaspoon/day & $16.1(15.6,16.6)$ & $14.6(14,15.2)$ & $15(14.5,15.5)$ & $15(14.5,15.4)$ & 0.002 \\
\hline Total fat, g/day & $75.8(75,76.6)$ & $75.9(75.1,76.8)$ & $77(75.9,78.1)$ & $78.1(77.2,79.1)$ & $<0.001$ \\
\hline PUFA, g/day & $24.5(24.2,24.8)$ & $24.2(23.8,24.6)$ & $24.9(24.5,25.2)$ & $25.4(25,25.8)$ & $<0.001$ \\
\hline MUFA, g/day & $26.5(26.2,26.9)$ & $26.8(26.4,27.1)$ & $27.1(26.6,27.6)$ & $27.6(27.2,28.1)$ & $<0.001$ \\
\hline SFA, g/day & $17.8(17.5,18.1)$ & $18.1(17.8,18.4)$ & $18.2(17.8,18.6)$ & $18.2(17.9,18.5)$ & 0.092 \\
\hline Solid fat, g/day & $31.8(31.3,32.3)$ & $31.3(30.6,32)$ & $32.9(32.3,33.5)$ & $34(33.2,34.9)$ & $<0.001$ \\
\hline \multicolumn{6}{|l|}{ Other dietary constituents } \\
\hline Caffeine, mg/day & $68.5(62.7,74.3)$ & $125(118.7,131.4)$ & $202.4(196.4,208.5)$ & $380(365.4,394.7)$ & $<0.001$ \\
\hline Calcium, mg/day & $953.2(933.2,973.3)$ & $942.4(920,964.7)$ & $939.7(918.5,961)$ & $939.4(915.3,963.4)$ & 0.333 \\
\hline Potassium, mg/day & $2529.7(2493.7,2565.7)$ & $2647.7(2605.8,2689.6)$ & $2697.6(2646.3,2749)$ & $2889(2850.6,2927.5)$ & $<0.001$ \\
\hline Magnesium, mg/day & $291.1(286.3,295.8)$ & $304.5(297.9,311.2)$ & $307.1(300.3,313.8)$ & $317(311.6,322.4)$ & $<0.001$ \\
\hline Vitamin C, mg/day & $88.6(84.4,92.8)$ & $84.8(80.9,88.7)$ & $81.2(76.5,85.9)$ & $73.6(69.8,77.4)$ & $<0.001$ \\
\hline Vitamin D, mcg/day & $4.7(4.5,4.9)$ & $4.8(4.6,5)$ & $4.7(4.4,5)$ & $4.5(4.2,4.7)$ & 0.247 \\
\hline Sodium, mg/day & $3432.8(3394.6,3470.9)$ & $3445.2(3396.1,3494.2)$ & $3371.5(3325.1,3417.9)$ & $3383.1(3325.9,3440.3)$ & 0.049 \\
\hline Cholesterol, mcg/day & $273.5(267.8,279.1)$ & $288.6(279.2,298)$ & $292.9(282.7,303.2)$ & $291.8(281.8,301.8)$ & 0.002 \\
\hline Alcohol, g/day & $7(6.2,7.8)$ & $9(8.2,9.9)$ & $9.6(8.6,10.6)$ & $10.1(8.9,11.2)$ & $<0.001$ \\
\hline \multicolumn{6}{|l|}{ Nutrient density/diet quality } \\
\hline NRF9.3 & $423.5(417.1,430)$ & $435.6(428.4,442.8)$ & $428.4(420.4,436.4)$ & $425.5(418.4,432.6)$ & 0.596 \\
\hline HEI-2015 & $51.2(50.6,51.8)$ & $52.8(52,53.5)$ & $52.4(51.7,53.1)$ & $51.8(51.1,52.6)$ & 0.076 \\
\hline
\end{tabular}

a Adjusted for energy, age, gender, race/ethnicity and family income to poverty ratio. 


\subsection{Coffee Source Locations by Age and Socio-Demographics}

Figure 1 shows the distribution of coffee source locations in the total population overall and by age group, race/ethnicity, education and family income. In the total population, $75.2 \%$ of coffee came from stores, $8.7 \%$ from fast food restaurants, which includes quick-service coffee shops, $4.3 \%$ from convenience stores, $3.8 \%$ from someone else (e.g., gift), 3.4\% from restaurants, $2.9 \%$ from a common coffee pot, and $1.6 \%$ from other sources.
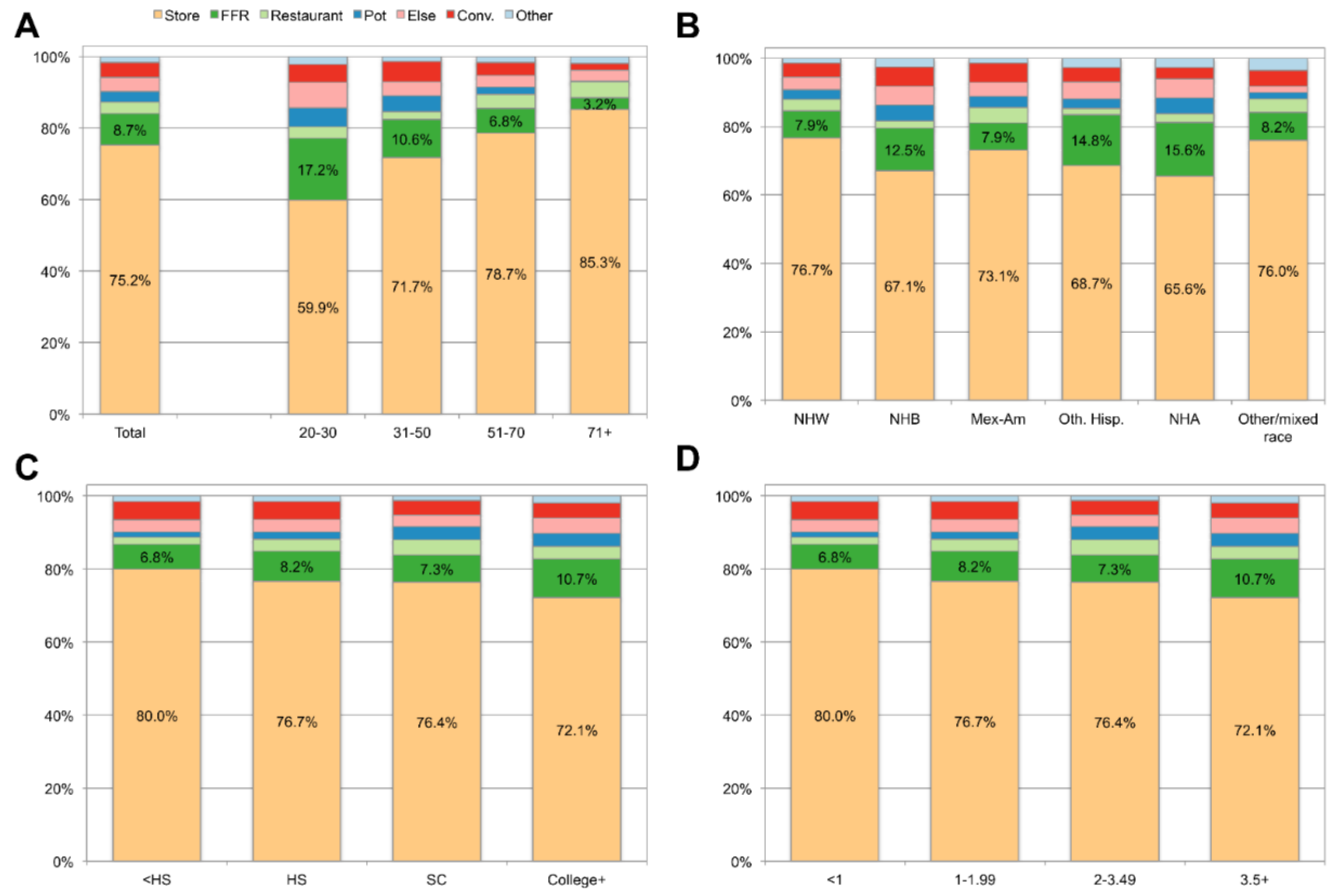

Figure 1. Sources of coffee overall and by age group (Panel A), race/ethnicity (Panel B), education (Panel C), and family income-to-poverty ratio (Panel D). Acronyms: FFR stands for fast food restaurant, Pot stands for common coffee pot, Conv stands for convenience store; NHW stands for non-Hispanic White, NHB stands for non-Hispanic Black, Mex-Am stands for Mexican-American, Oth. Hisp. stands for other Hispanic, NHA stands for non-Hispanic Asian, HS stands for HS, SC stands for Some college.

Across all groups, grocery stores were the most common source of coffee ( $>59 \%$ in all groups), but distinct purchase patterns by location and population subgroup were also observed. Among older adults, more than $85 \%$ of coffee came from grocery stores as compared to $59 \%$ among younger adults. Younger adults were more likely to obtain coffee from fast food restaurants, convenience stores, someone else, cafeteria, and common coffee pot. Among younger adults, fast food restaurants contributed $17.2 \%$ of coffee, as compared to only $3.2 \%$ amongst the oldest adults.

Some differences were also observed by race/ethnicity. Most likely to get coffee from stores were non-Hispanic Whites (75.7\%), Mexican Americans (73.6), Hispanic (72.3\%) and other groups (77\%). Least likely were non-Hispanic Black (63.0) and non-Hispanic Asian (63.8\%) groups. Non-Hispanic Black adults were more likely to get coffee from fast food restaurants and convenience stores as compared to non-Hispanic White adults. Groups with more education and with higher incomes tended to get coffee from fast food restaurants more than other groups and those with less education were more likely to get coffee from convenience stores. Data by gender are not shown in the graphs, but women were more likely to get coffee from stores ( $77.7 \%$ for women compared to $73.1 \%$ for men). Men were more likely to take coffee from a common coffee pot than women ( $3.9 \%$ for men vs. $1.8 \%$ for women). 


\section{Discussion}

Based on the 2015-2020 Dietary Guidelines [15], moderate coffee consumption-up to three to five 8-oz cups/day containing up to $400 \mathrm{mg} /$ day of caffeine—can be incorporated into healthy eating styles. Those levels of coffee consumption ( 740 to $1200 \mathrm{~mL} /$ day) have not been associated with an increased risk of premature death, especially from cardiovascular disease, or with higher mortality from cancer [15]. The present analyses showed that mean coffee consumption among coffee drinkers was $544.7 \mathrm{~g} /$ day $(18.3 \mathrm{oz})$, well within the DGA guidelines for a healthy diet.

About 59\% of NHANES 2011-2016 participants consumed coffee on one or both days of dietary data collection. These data contrast with an estimated of 79\% based on 2003-2006 NHANES. However, Loftfield et al. [3] used a broader definition, identifying coffee drinkers as those who reported ever consuming coffee in the previous 12 months on the FFQ or reported coffee intake on one or more 24-h dietary recalls. Using different income cut points, the present findings confirmed a significant effect of income that applied not only to coffee consumption but also to coffee purchase location. Most of the coffee $(74 \%)$ was purchased in grocery stores for preparation and consumption at home.

The present analyses of nationally representative NHANES data are consistent with 2018 industry reports that $64 \%$ of Americans aged $\geq 18$ years said they had a cup of coffee the previous day [12,13]. The figure for 2017 was $62 \%$, according to results of a survey commissioned by the National Coffee Association (NCA) and available for purchase. The present finding that away-from-home coffee was more typical of younger participants and groups with higher education and incomes was also consistent with industry reports $[12,13]$.

The current consensus is the "healthy" beverages are plain drinking water and coffee and tea without added sweeteners. Each of those beverages follows distinct patterns of consumption $[4,5]$. The present data provide a direct comparison with previously published analyses of both water and tea consumption patterns among US adults in the same NHANES 2011-2016 data [4]. Compared to widespread water and coffee consumption, only $20.8 \%$ of adults were tea consumers [4]. For both coffee and tea, percent consumers and amounts consumed increased with age. However, whereas $74 \%$ of adults in the $>70$ age group drank coffee, only $27 \%$ in that age group drank tea. For coffee, the effect of income was significant but the effect of education was not. For tea, the effects of both income and education were significant [4]. For both tea and coffee there were significant effects of race/ethnicity. Coffee and tea consumption were higher among non-Hispanic Whites than among non-Hispanic Blacks and other groups.

A social gradient was observed for drinking water. Higher tap water consumption was associated with higher incomes, but bottled water was not. Non-Hispanic Whites consumed most tap water (781 mL/day), and Mexican Americans consumed most bottled water $(605 \mathrm{~mL} /$ day $)$. Whereas the US consumption patterns for drinking water, coffee, tea and diet soft drinks appear to be associated with higher socioeconomic status, the consumption of caloric sugar sweetened beverages follows the opposite social gradient [16].

Identifying the coffee purchase location was a novel component of this study [16-18]. About $74 \%$ of coffee was purchased in stores to be prepared and consumed at home. This finding is also consistent with industry sources showing that at-home preparation continues to be dominant $[12,13]$. We now provide additional data showing that consumption patterns for coffee consumed at cafes and other out-of-home locations varied by age, income, and race/ethnicity.

The present estimates of dietary nutrient density among coffee consumers and non-consumers provide some parallels as well as contrasts with tea consumption. Coffee consumption among adults in the 2011-2016 NHANES sample was associated with greater compliance with the 2015-2020 Dietary Guidelines for Americans, as assessed by higher HEI-2015 scores [25]. Each 3\% reduction in total dietary energy from empty calories leads to a 2-point improvement in HEI-2015. However, the observed effects of coffee on diet quality were not nearly as pronounced as those that had previously been observed for tea. Tea consumers in the same 2011-2016 NHANES database had diets that were lower in added sugars but higher in protein, vitamins and minerals. Coffee consumers had diets that were lower in 
total carbohydrates and in added sugars but were higher in total fats. Diets of coffee consumers were higher and potassium and magnesium (coffee is a top dietary source of potassium after milk) but they were not higher in calcium or vitamin $\mathrm{D}$ as compared to the non-consumers Consistent with past reports, diets of coffee consumers were higher in alcohol. The overall effect on HEI 2015 scores was weak, although it remained significant after adjusting for covariates.

The Dietary Guidelines 2015-2020 noted that while coffee consumption was not detrimental to health, coffee beverages may include calories from added sugars and/or saturated fat (such as cream, whole or $2 \%$ milk, and creamer), both of which should be limited [15]. The present analyses showing that the diets of coffee consumers were actually lower in added sugar ought to ease the concerns expressed in Dietary Guidelines 2015-2020. It may be that coffee drinkers consumed less sugar sweetened beverages (SSB) due to their more advanced age and higher socioeconomic status. For those groups, caloric SSB may have been replaced by coffee. However, diets of coffee consumers were also higher in total fats including MUFA and PUFA but also saturated and solid fats and cholesterol. Calcium intakes of which milk is a main source did not differ between coffee consumers and non-consumers. The present association between caffeine intakes and alcohol consumption has been observed before in published analyses of the NHANES 2007-2012 data [9].

The present study had limitations. The NHANES studies are based on a cross-sectional design, which means that causality cannot be inferred. NHANES $24 \mathrm{~h}$ dietary recalls were based on self-report. Assessments of dietary nutrient density lacked novel data bases such as polyphenols. Whereas tea is the main source of bioactive flavonoids [5], coffee along with wine is among the main sources of dietary polyphenols $[28,29]$. Nevertheless, the scale and representativeness of the NHANES sample make it the premier study of dietary intakes in the US and the foundation of food and nutrition policy.

\section{Conclusions}

The present analyses provide additional evidence regarding the relation between the consumption of beverages and achieving nutrient and food-based dietary guidelines. Mean coffee consumption among coffee consumers was within the DGA guidelines as were the mean intakes of caffeine. Among adults, the consumption of coffee, tea, and drinking water was associated with improved dietary nutrient density and higher incomes. A polyphenol database may prove useful for designing a new guidance system for beverage consumption in the US [30].

Author Contributions: Conceptualization, J.C.R., C.S.R., C.D.R., and A.D. Database methodology, C.D.R. Formal analyses, C.D.R. Original draft, A.D. Writing, review, and editing, J.C.R., C.S.R., C.D.R. and A.D. Funding acquisition, J.C.R., C.S.R. All authors have read and agreed to the published version of the manuscript.

Funding: Analyses of publicly available NHANES 2011-2016 data were supported by Keurig Pepper.

Conflicts of Interest: J.C.R. and C.S.R. are employed by Keurig Pepper. A.D. has received grants, contracts, honoraria and speaking fees from both public and private entities with an interest in the nutrient profiling of individual foods and total diets. C.D.R. has no conflicts of interest to report. The funders had no role in the design of the study; or in the collection, analyses, or interpretation of publicly available federal NHANES data. The views and opinions expressed here are those of the authors and do not necessarily reflect those of Keurig Pepper.

\section{References}

1. Landais, E.; Moskal, A.; Mullee, A.; Nicolas, G.; Gunter, M.J.; Huybrechts, I.; Overvad, K.; Roswall, N.; Affret, A.; Fagherazzi, G.; et al. Coffee and Tea Consumption and the Contribution of Their Added Ingredients to Total Energy and Nutrient Intakes in 10 European Countries: Benchmark Data from the Late 1990s. Nutrients 2018, 10, 725. [CrossRef] [PubMed]

2. Loftfield, E.; Freedman, N.D.; Dodd, K.W.; Vogtmann, E.; Xiao, Q.; Sinha, R.; I Graubard, B. Coffee Drinking Is Widespread in the United States, but Usual Intake Varies by Key Demographic and Lifestyle Factors. J. Nutr. 2016, 146, 1762-1768. [CrossRef] [PubMed]

3. Vieux, F.; Maillot, M.; Rehm, C.D.; Barrios, P.; Drewnowski, A. Trends in tap and bottled water consumption among children and adults in the United States: Analyses of NHANES 2011-16 data. Nutr. J. 2020, 19, 10-14. [CrossRef] [PubMed] 
4. Vieux, F.; Maillot, M.; Rehm, C.; Drewnowski, A. Tea Consumption Patterns in Relation to Diet Quality among Children and Adults in the United States: Analyses of NHANES 2011-2016 Data. Nutrients 2019, 11, 2635. [CrossRef]

5. Vieux, F.; Maillot, M.; Rehm, C.D.; Drewnowski, A. Flavonoid Intakes in the US Diet Are Linked to Higher Socioeconomic Status and to Tea Consumption: Analyses of NHANES 2011-16 Data. J. Nutr. 2020, 150, 2147-2155. [CrossRef]

6. Maillot, M.; Rehm, C.D.; Vieux, F.; Rose, C.M.; Drewnowski, A. Beverage consumption patterns among 4-19 y old children in 2009-14 NHANES show that the milk and $100 \%$ juice pattern is associated with better diets. Nutr. J. 2018, 17, 54. [CrossRef]

7. Miranda, A.M.; Steluti, J.; Fisberg, R.M.; Marchioni, D.M.L. Association between Coffee Consumption and Its Polyphenols with Cardiovascular Risk Factors: A Population-Based Study. Nutrients 2017, 9, 276. [CrossRef]

8. Benson, S.; Unice, K.M.; Glynn, M.E. Hourly and daily intake patterns among U.S. caffeinated beverage consumers based on the National Health and Nutrition Examination Survey (NHANES, 2013-2016). Food Chem. Toxicol. 2019, 125, 271-278. [CrossRef]

9. Lieberman, H.R.; Agarwal, S.; Fulgoni, V.L. Daily patterns of caffeine intake and the association of intake with multiple sociodemographic and lifestyle factors in US adults Based on the NHANES 2007-2012 Surveys. J. Acad. Nutr. Diet. 2019, 119, 106-114. [CrossRef]

10. Ahluwalia, N.; Herrick, K. Caffeine intake from food and beverage sources and trends among children and adolescents in the United States: Review of national quantitative studies from 1999 to 2011. Adv. Nutr. 2015, 6, 102-111. [CrossRef]

11. Drewnowski, A.; Rehm, C. Sources of Caffeine in Diets of US Children and Adults: Trends by Beverage Type and Purchase Location. Nutrients 2016, 8, 154. [CrossRef] [PubMed]

12. Key Coffee Statistics. Available online: https://myfriendscoffee.com/usa-coffee-statistics/ (accessed on 28 June 2020).

13. National Coffee Association the 2020 National Coffee Data Trends Report. Available online: https://www. ncausa.org/Industry-Resources/Market-Research/NCDT (accessed on 16 August 2020).

14. National Center for Health Statistics NHANES-About the National Health and Nutrition Examination Survey. Available online: https://www.cdc.gov/nchs/nhanes/about_nhanes.htm (accessed on 22 July 2019).

15. US Department of Health and Human Services. Dietary Guidelines for Americans 2015-2020; Skyhorse Publishing Inc.: New York, NY, USA, 2017; ISBN 9780160934650.

16. Drewnowski, A.; Rehm, C.D. Consumption of added sugars among US children and adults by food purchase location and food source. Am. J. Clin. Nutr. 2014, 100, 901-907. [CrossRef] [PubMed]

17. Nishi, S.K.; Jessri, M.; L'Abbe, M. Assessing the Dietary Habits of Canadians by Eating Location and Occasion: Findings from the Canadian Community Health Survey, Cycle 2.2. Nutrients 2018, 10, 682. [CrossRef] [PubMed]

18. Drewnowski, A.; Rehm, C.D. Sodium Intakes of US Children and Adults from Foods and Beverages by Location of Origin and by Specific Food Source. Nutrients 2013, 5, 1840-1855. [CrossRef] [PubMed]

19. Shan, Z.; Rehm, C.D.; Rogers, G.; Ruan, M.; Wang, D.D.; Hu, F.B.; Mozaffarian, D.; Zhang, F.F.; Bhupathiraju, S.N. Trends in Dietary Carbohydrate, Protein, and Fat Intake and Diet Quality Among US Adults. 1999-2016. JAMA 2019, 322, 1178-1187. [CrossRef]

20. Center for Health Statistics. N. NHANES Phone Follow-up Dietary Interviewer Procedures Manual. Available online: https://www.cdc.gov/nchs/data/nhanes/nhanes_09_10/phone_follow_up_dietary_ procedures_manual_mar_2010.pdf (accessed on 23 July 2019).

21. Moshfegh, A.J.; Rhodes, D.G.; Baer, D.J.; Murayi, T.; Clemens, J.C.; Rumpler, W.V.; Paul, D.R.; Sebastian, R.S.; Kuczynski, K.J.; A Ingwersen, L.; et al. The US Department of Agriculture Automated Multiple-Pass Method reduces bias in the collection of energy intakes. Am. J. Clin. Nutr. 2008, 88, 324-332. [CrossRef]

22. U.S. Department of Agriculture. A.R.S. USDA Food and Nutrient Database for Dietary Studies 2013-2014. Food Surveys Research Group Home Page. Available online: https://ata.nal.usda.gov/dataset/food-andnutrient-database-dietary-studies-fndds (accessed on 23 July 2019).

23. Bowman, S.A.; Clemens, J.C.; Thoerig, R.C.; Friday, J.E.; Shimizu, M.; Moshfegh, A.J. Food Patterns Equivalents Database 2009-2010: Methodology and User Guide; Food Surveys Research Group, Beltsville Human Nutrition Research Center, Agricultural Research Service, United States Department of Agriculture: Washington, DC, USA, 2013. 
24. Krebs-Smith, S.M.; Pannucci, T.; Subar, A.F.; I Kirkpatrick, S.; Lerman, J.L.; Tooze, J.A.; Wilson, M.M.; Reedy, J. Update of the Healthy Eating Index: HEI-2015. J. Acad. Nutr. Diet. 2018, 118, 1591-1602. [CrossRef]

25. Vieux, F.; Maillot, M.; Rehm, C.D.; Drewnowski, A. Designing Optimal Breakfast for the United States Using Linear Programming and the NHANES 2011-2014 Database: A Study from the International Breakfast Research Initiative (IBRI). Nutrients 2019, 11, 1374. [CrossRef]

26. Centers for Disease Control and Prevention. NHANES-NCHS Research Ethics Review Board Approval. Available online: https://www.cdc.gov/nchs/nhanes/irba98.htm (accessed on 23 July 2019).

27. Centers for Disease Control and Prevention. NHANES-National Health and Nutrition Examination Survey Homepage. Available online: https://www.cdc.gov/nchs/nhanes/index.htm (accessed on 23 July 2019).

28. Williamson, G. The role of polyphenols in modern nutrition. Nutr. Bull. 2017, 42, 226-235. [CrossRef]

29. Fukushima, Y.; Tashiro, T.; Kumagai, A.; Ohyanagi, H.; Horiuchi, T.; Takizawa, K.; Sugihara, N.; Kishimoto, Y.; Taguchi, C.; Tani, M.; et al. Coffee and beverages are the major contributors to polyphenol consumption from food and beverages in Japanese middle-aged women. J. Nutr. Sci. 2014, 3. [CrossRef]

30. Popkin, B.; E Armstrong, L.; Bray, G.M.; Caballero, B.; Frei, B.; Willett, W.C. A new proposed guidance system for beverage consumption in the United States. Am. J. Clin. Nutr. 2006, 83, 529-542. [CrossRef] [PubMed]

(C) 2020 by the authors. Licensee MDPI, Basel, Switzerland. This article is an open access article distributed under the terms and conditions of the Creative Commons Attribution (CC BY) license (http://creativecommons.org/licenses/by/4.0/). 